\title{
Drug Susceptibility Pattern from Tuberculosis Patients in Region of Macedonia Greece
}

\author{
G. Kazdaglis ${ }^{1}$, K. Manika², P. Ioannidis ${ }^{3}$, D. Papaventsis ${ }^{3}$, E. Vogiatzakis ${ }^{3}$, E. Papakala ${ }^{2}$, M. Panopoulou ${ }^{4}$, \\ A. Galatas', A. Melidou1, I. Kioumis'2, N. Malisiovas', G. Gioula1 \\ ${ }^{1}$ Department of Medical Microbiology, Aristotle University of Thessaloniki, Thessaloniki, Greece \\ ${ }^{2}$ Pulmonary Department, Aristotle University of Thessaloniki, G. Papanikolaou Hospital, Thessaloniki, Greece \\ ${ }^{3}$ Microbiology Laboratory and National Reference Center for TB, Sotiria Chest Diseases Hospital, Athens, Greece \\ ${ }^{4}$ Microbiology Department, Dimokritio University of Thrace, Alexandroupoli, Greece \\ ${ }^{5}$ Tuberculosis Laboratory, G. Papanikolaou Hospital, Thessaloniki, Greece \\ Email: georgioskazdaglis@live.com
}

How to cite this paper: Kazdaglis, G., Manika, K., Ioannidis, P., Papaventsis, D., Vogiatzakis, E., Papakala, E., Panopoulou, M., Galatas, A., Melidou, A., Kioumis, I., Malisiovas, N. and Gioula, G. (2016) Drug Susceptibility Pattern from Tuberculosis Patients in Region of Macedonia Greece. Journal ot Tuberculosis Research, 4, 92-97.

http://dx.doi.org/10.4236/jtr.2016.43011

Received: April 21, 2016

Accepted: August 14, 2016

Published: August 17, 2016

Copyright $\odot 2016$ by authors and Scientific Research Publishing Inc. This work is licensed under the Creative Commons Attribution International License (CC BY 4.0).

http://creativecommons.org/licenses/by/4.0/ (c) (7) Open Access

\begin{abstract}
Tuberculosis $(\mathrm{TB})$ remains one of the world's deadliest diseases. Increasing rates of drug-resistant tuberculosis in Eastern Europe, Asia and sub-Saharan Africa now threaten to undermine the gains made by worldwide tuberculosis control efforts. The region of Macedonia in North Greece is an entrance gate of thousands of immigrants, moving mainly from East European countries with high tuberculosis prevalence to Greece and the whole Europe. Our study determines the drug susceptibility pattern of new TB cases in the region of Macedonia, Greece. A total of 63 M. tuberculosis strains were isolated by cultivation between January 2012 and December 2014 in Macedonia, North Greece. After microscopic examination with Ziehl-Neelsen staining, clinical samples were simultaneously tested by two methods: conventional culture method on the Löwenstein-Jensen (L-J) slants for 8 weeks (at $370^{\circ} \mathrm{C}$ ) and molecular method Genotype MTBDR plus (Hain-Lifescience). According to the study results, 2 out of 63 strains (3.2\%) were resistant to both isoniazid (INH) and rifampicin (RMP). Additionally, 3 strains (4.8\%) were INH mono-resistant. Statistical analysis demonstrated that there was no statistically significant difference in presence of resistance according to patients' gender or origin (Greeks or immigrants). It is clear that the implementation of an efficient nationwide system for the surveillance, diagnosis and treatment of TB is essential. The best strategy in order to control, and prevent TB includes, first of, all a rapid diagnosis and initiation of treatment, something which is the most important for public health.
\end{abstract}

\section{Keywords}

Tuberculosis, Resistance, Macedonia Region, Greece 


\section{Introduction}

Tuberculosis (TB) remains one of the most devastating and widespread infections in the world [1] [2]. In 2014, an estimated 9.6 million people developed TB and 1.5 million died from the disease, 392,000 of whom were human immunosuppressive virus (HIV) positive. It is estimated that 66 million lives were saved between 1995 and 2014, through effective diagnosis and treatment. However, given that most deaths from TB are preventable, the death toll from the disease is still unacceptable high [3]. In Greece, the case notification rate was 4.7 cases per 100,000 inhabitants in 2012, while less than $50 \%$ of all reported TB cases were confirmed by bacterial culture [4]. Moreover, underreporting is an important issue for TB control in Greece (it is estimated 77\% - 81\%). Various limitations in the national TB monitoring system exist, many of them due to the economic crisis. There are also access limitations [5]-[7]. Furthermore, migration from regions with high TB incidence (for example, Former Soviet Union countriesFSU) possibly leads to further underestimation of the TB burden and facilitates further spread of the disease. Reluctance to notify TB cases and failure to collect data at regional and national level makes TB surveillance and trend analysis problematic [8]. It is also noteworthy that the percentage of cases due to resistant strains is increasing worldwide, according to World Health Organization (WHO) [9]. It is estimated that, on a global level, $3.7 \%$ of TB treatment-new cases and $20 \%(13 \%-26 \%)$ of previously treated TB cases have multidrug-resistant TB (MDR-TB) i.e. resistant to both isoniazid (INH) and (RMP). By 2015, 105 countries had reported cases of extensively drug resistant TB (XDR-TB), including 13 countries and territories that had reported more than ten XDR-TB cases in a single year. The average percentage of XDR-TB cases was $9.6 \%$ (95\% CI: $8.1 \%-11 \%$ [10]. In Greece, resistance ratio is also increasing and MDR-TB represents $3 \%, 4 \%$ of TB cases in Greeks (lower than the EU average 4\%, 6\%) and 25\% in foreign born patients [8]. In our region there is access to TB diagnosis, through the free national healthcare system. There were no national guidelines for TB-management before 2014. The aim of the present study is to determine the drug susceptibility pattern of new TB cases in the region of Macedonia.

\section{Material and Method}

Our study was a cross-sectional study of new TB cases, aged $>18$ years. A total of $63 M$. tuberculosis strains were isolated by cultivation between January 2012 and December 2014 in Macedonia, North Greece. Our samples were collected from the "G. Papanikolaou" Hospital in Thessaloniki which is the major hospital for TB management in Macedonia region, Greece. The strains were selected from symptomatic patients with a diagnosis of pulmonary and extra-pulmonary tuberculosis. No ethical approval was required for this study. After microscopic examination with Ziehl-Neelsen staining, clinical samples were simultaneously tested by two methods: conventional culture method on the Löwenstein-Jensen (L-J) slants for 8 weeks (at $37^{\circ} \mathrm{C}$ ) and molecular method Genotype MTBDR plus (Hain-Lifesciene). The cultures were subjected to phenotypic identification based on growth and colony characteristics, pigment production and bi- 
ochemical tests (Pfeiffer GE. Mycobacterium: General characteristics, Laboratory detection and Staining Procedures. Manual of Clinical Microbiology 9th Edition ASM 2007; 543 - 572). Conventional drug susceptibility testing was determined on LJ, by the proportion method with resistance ratio. The susceptibility of Mycobacteria was analyzed for the 2 major anti-tuberculosis agents, isoniazid (INH) and rifampicin (RMP). Two concentrations were analyzed to both agents as follow: INH $0.2 \mathrm{~g} / \mathrm{ml}, 0.4 \mathrm{~g} / \mathrm{ml}$ and RMP $40 \mathrm{~g} / \mathrm{ml}, 80 \mathrm{~g} / \mathrm{ml}$ (Pfeiffer GE. Mycobacterium: General characteristics, Laboratory detection and Staining Procedures. Manual of Clinical Microbiology 9th Edition ASM 2007; 543 - 572). Extraction of DNA from clinical samples was performed using the Qiagen DNA mini kit method, According to the manufacturers' instructions. The confirmation of the existence of Mycobacterium tuberculosis DNA was performed by Real time PCR using artus ${ }^{\circledast}$ M. tuberculosis RG PCR Kit (Sacace Biotechnologies), where detection is based on the amplification of specific regions of the mycobacterial genome (DNA fragments of IS 6110 insertion). The detection of resistance to major anti-TB drugs RMP and INH was performed with the line probe assay Genotype MTBDR plus (Hain-Lifescience), Germany, according to manufacturer's instructions, as shown in Figure 1. The identification of RMP resistance is enabled by the detection of the most significant mutations of the rpoB gene (coding for the $\beta$-subunit of the RNA polymerase). For testing the high level isoniazid resistance, the katG gene (coding for the catalase peroxidase) is examined and for testing the low level INH resistance, the promoter region of the inhA gene (coding for the NADH enoyl ACP reductase) is analyzed. Moreover, Human Immunosuppressive Virus (HIV) 1 and 2 testing was performed to all patients. All technologies used are WHO recommended and there is quality assurance program in the Greek National Reference Laboratory for Mycobacteria (NRLM), Sotiria Chest Diseases Hospital, where the above molecular tests were performed.

Chi square test and Fischer's exact test was used for comparisons between nonparametric variables (presence of resistance to INH and/or RMP between male and female patients and between Greeks and immigrants). Un-paired t-test was used for comparison of age between Greeks and immigrants and patients with any resistance vs patients with totally susceptible strains (SPSS statistical package $\mathrm{v} 22$ )

\section{Result}

The mean age of the patients was 47.8 years ( 18 - 85 years, 42 males and 21 females); while 24 out of the 63 patients were immigrants and they came from Georgia, Albania, Pakistan, Bangladesh, Russia, Ukraine, Bulgaria, Moldavia and China. Immigrants were significantly older than Greek patients $(36.68 \pm 11.92$ vs $48.17 \pm 20.46, \mathrm{p}<0.001)$ All patients were new TB cases, HIV 1 and 2 negative and were not related to each other, according to their background.

Two out of 63 strains (3.2\%) were MDR-TB. Additionally, 3 strains (4.8\%) were INH mono-resistant (Figure 1). No statistically significant differences in the presence of resistance to INH and/or RMP were detected between Greeks and immigrants (X2 = $0.964, \mathrm{p}=0.326$, Fisher's exact test 0.209$)$ or between male and female patients $(\mathrm{X} 2=$ 


\begin{tabular}{|c|c|c|c|c|c|c|c|c|c|c|c|}
\hline \multicolumn{4}{|c|}{ GenoType MTBDRplus } & \multicolumn{2}{|c|}{ Strain ID } & \multicolumn{3}{|c|}{ GenoType MTBDRplus } & \multicolumn{3}{|c|}{ Strain ID } \\
\hline $\mathrm{INH}$ & RMP & rрoB & KatG & InhA & & $\underline{\mathrm{INH}}$ & RMP & rрoB & KatG & InhA & \\
\hline $\mathrm{S}$ & $\mathrm{S}$ & wt & wt & wt & 1 & $\mathrm{~S}$ & $\mathrm{~S}$ & wt & wt & $\overline{w t}$ & 15 \\
\hline S & $\mathrm{S}$ & wt & wt & wt & 2 & $\mathrm{~S}$ & $\mathrm{~S}$ & wt & wt & wt & 16 \\
\hline S & $\mathrm{S}$ & wt & wt & wt & 3 & $\mathrm{~S}$ & $\mathrm{~S}$ & wt & wt & wt & 17 \\
\hline $\mathrm{S}$ & $\mathrm{S}$ & wt & wt & wt & 4 & $\mathrm{~S}$ & $\mathrm{~S}$ & wt & wt & wt & 18 \\
\hline $\mathrm{R}$ & $\mathrm{S}$ & wt & wt & C-15T & 5 & $\mathrm{~S}$ & $\mathrm{~S}$ & wt & wt & wt & 19 \\
\hline S & $S$ & wt & wt & wt & 6 & $\mathrm{~S}$ & $\mathrm{~S}$ & wt & wt & wt & 20 \\
\hline $\mathrm{S}$ & $\mathrm{S}$ & wt & wt & wt & 7 & $\mathrm{~S}$ & $\mathrm{~S}$ & wt & wt & wt & 21 \\
\hline S & $\mathrm{S}$ & wt & wt & wt & 8 & $S$ & $S$ & wt & wt & wt & 22 \\
\hline $\mathrm{S}$ & $\mathrm{S}$ & wt & wt & wt & 9 & $\mathrm{~S}$ & $\mathrm{~S}$ & wt & wt & wt & 23 \\
\hline S & $S$ & wt & wt & wt & 10 & $S$ & $S$ & wt & wt & wt & 24 \\
\hline $\mathrm{R}$ & $\mathrm{S}$ & wt & wt & C-15T & 11 & $\mathrm{~S}$ & $S$ & wt & wt & wt & 25 \\
\hline $\mathrm{S}$ & $\mathrm{S}$ & wt & wt & wt & 12 & $\mathrm{~S}$ & $\mathrm{~S}$ & wt & wt & wt & 26 \\
\hline $\mathrm{R}$ & $S$ & wt & wt & C-15T & 13 & $S$ & $S$ & wt & wt & wt & 27 \\
\hline S & $\mathrm{S}$ & wt & wt & wt & 14 & $\mathrm{~S}$ & $S$ & wt & wt & wt & 28 \\
\hline \multicolumn{4}{|c|}{ GenoType MTBDRplus } & \multicolumn{2}{|c|}{ Strain ID } & \multicolumn{3}{|c|}{ GenoType MTBDRplus } & \multicolumn{3}{|c|}{ Strain ID } \\
\hline $\mathrm{INH}$ & RMP & rpoB & KatG & InhA & & $\mathrm{INH}$ & RMP & rpoB & KatG & InhA & \\
\hline $\mathrm{S}$ & $\mathrm{S}$ & wt & wt & wt & 29 & $\mathrm{~S}$ & $\mathrm{~S}$ & wt & wt & wt & 47 \\
\hline $\mathrm{S}$ & $\mathrm{S}$ & wt & wt & wt & 30 & $\mathrm{~S}$ & $\mathrm{~S}$ & wt & wt & wt & 48 \\
\hline S & $\mathrm{S}$ & wt & wt & wt & 31 & $\mathrm{~S}$ & $\mathrm{~S}$ & wt & wt & wt & 49 \\
\hline $\mathrm{S}$ & $\mathrm{S}$ & wt & wt & wt & 32 & $\mathrm{~S}$ & $\mathrm{~S}$ & wt & wt & wt & 50 \\
\hline $\mathrm{S}$ & $\mathrm{S}$ & wt & wt & wt & 33 & $\mathrm{~S}$ & $\mathrm{~S}$ & wt & wt & wt & 51 \\
\hline S & $\mathrm{S}$ & wt & wt & wt & 34 & $\mathrm{~S}$ & $\mathrm{~S}$ & wt & wt & wt & 52 \\
\hline $\mathrm{S}$ & $\mathrm{S}$ & wt & wt & wt & 35 & $\mathrm{~S}$ & $\mathrm{~S}$ & wt & wt & wt & 53 \\
\hline S & $\mathrm{S}$ & wt & wt & wt & 36 & $\mathrm{~S}$ & $\mathrm{~S}$ & wt & wt & wt & 54 \\
\hline $\mathrm{S}$ & $\mathrm{S}$ & wt & wt & wt & 37 & $\mathrm{~S}$ & $\mathrm{~S}$ & wt & wt & wt & 55 \\
\hline S & $\mathrm{S}$ & wt & wt & wt & 38 & $\mathrm{~S}$ & $\mathrm{~S}$ & wt & wt & wt & 56 \\
\hline S & $\mathrm{S}$ & wt & wt & wt & 39 & $\mathrm{~S}$ & $\mathrm{~S}$ & wt & wt & wt & 57 \\
\hline $\mathrm{S}$ & S & wt & wt & wt & 40 & $\mathrm{~S}$ & $\mathrm{~S}$ & wt & wt & wt & 58 \\
\hline S & $\mathrm{S}$ & wt & wt & wt & 41 & $\mathrm{~S}$ & $\mathrm{~S}$ & wt & wt & wt & 59 \\
\hline $\mathrm{S}$ & $\mathrm{S}$ & wt & wt & wt & 42 & $\mathrm{~S}$ & $\mathrm{~S}$ & wt & wt & wt & 60 \\
\hline $\mathrm{S}$ & $\mathrm{S}$ & wt & wt & wt & 43 & $\mathrm{R}$ & $\mathrm{R}$ & S531L & S315T1 & wt & 61 \\
\hline S & $\mathrm{S}$ & wt & wt & wt & 44 & $\mathrm{~S}$ & $\mathrm{~S}$ & wt & wt & wt & 62 \\
\hline S & $\mathrm{S}$ & wt & wt & wt & 45 & $\mathrm{R}$ & $\mathrm{R}$ & S531L & S315T1 & L C-15T & 63 \\
\hline S & $\mathrm{S}$ & wt & wt & wt & 46 & & & & & & \\
\hline
\end{tabular}

Figure 1. Line probe assay Genotype MTBDR plus results for the 63 M. tuberculosis strains.

$1.865, \mathrm{p}=0.172$, Fisher's exact test 0.166 ). Age did not significantly differ according to presence of resistance. Both MDR-TB strains were isolated from patients who were male, aged 64 and 26 years old respectively. The 64-year-old patient was a Greek patient, under chemotherapy due to stomach cancer, while the younger one was an immigrant from Ukraine.

\section{Discussion and Conclusion}

Despite the remarkable efforts to control $\mathrm{TB}$, the disease remains one of the most serious infectious diseases, with incalculable financial impact on health care system of the country. Moreover, important issues regarding drug resistance have emerged. According to the present study, $3.2 \%$ of the isolated strains were MDR-TB, while $4.8 \%$ of them were INH mono-resistant. Resistance to first-line anti-TB drugs remains higher in Greece than in most other countries in Western Europe [11]. On the other hand, much higher INH resistance rates were observed in FSU countries, for example Kazakhstan, Latvia, Russia, Georgia, Estonia and Lithuania. Moreover, MDR-TB was also much higher in the above FSU countries as well, than in Greece (3.2\%) and the rest of Europe (median European MDR rate 1.0\%) [12]. Multi-drug resistant TB is more prevalent in Greece, in comparison with other Western European countries. This is likely the result of immigration, late diagnosis and inadequate treatment of index cases within Greece. 
Although the statistical analysis of the results of the present study demonstrated that there were no statistically significant associations between patients' origin and drugresistance, previous and current data confirm that the absolute number of resistant cases in immigrants still appears to be increasing [8] [13]. Another study that was conducted in N. Greece, during 2007-2010, demonstrates that TB cases among immigrants tend to increase, contributing significantly to overall higher incidence rates. Additionally, immigrants also tend to present with more severe disease and emerge more frequent relapses and higher prevalence of resistant and MDR-TB [14]. According to the most recent data from Hellenic Centre for Disease Control and Prevention (HCDCP), the proportion of the MDR-TB strains in Greece during 2009-2011 was 1.7\% - 1.9\% for natives and 4.6\% - 4.8\% for immigrants [15]. Additionally, from 2006 to 2009, 13 XDR-TB cases were reported at the National Reference Laboratory for Mycobacteria (NRLM) in Athens: nine cases among Greek nationals, most of them repatriated from the Former Soviet Union and the remaining four were recorded among migrants. XDR-TB ratio among MDR-TB cases was 19\% [8]. Most recently, the first fatal case of XDR-TB was reported in an injecting drug user (IDU) in Athens, Greece, co-infected with HIV and Hepatitis C Virus (HCV). Despite immediate initiation of treatment, the patient's condition gradually deteriorated and he died 16 days after hospital admission due to multiple organ failure [16]. A gradual and significant increase in the number of MDR-TB cases was also observed in the United Kingdom, with a concomitant increase in the severity of drug resistance, particularly among aminoglycosides. These resistance patterns are largely determined by non-UK-born individuals [17]. Globally, according to drug resistance surveillance data from World Health Organization (WHO) 480,000 people developed MDR-TB in 2014 and 190,000 people died. XDR-TB has been reported by 105 countries in 2014. On average, an estimated $9.7 \%$ of people with MDR$\mathrm{TB}$ have XDR-TB [18]. It is clear that the implementation of an efficient nationwide system for the surveillance, diagnosis and treatment of tuberculosis is essential. Although the Hellenic Center for Disease Control and Prevention (HCDCP) has worked for the improvement of underreporting and for more effective control of the disease, there is still a long way to go [19]. The best strategy in order to control and prevent TB includes, first of all, a rapid diagnosis and initiation of treatment, something which is the very important for public health.

\section{References}

[1] Lim, S.S., Vos, T., Flaxman, A.D., Danaei, G., Shibuya, K., Adair-Rohani, H., et al. (2012) A Comparative Risk Assessment of Burden of Disease and Injury Attributable to 67 Risk Factors and Risk Factor Clusters in 21 Regions, 1990-2010: A Systematic Analysis for the Global Burden of Disease Study 2010. The Lancet, 380, 2224-2260. http://dx.doi.org/10.1016/S0140-6736(12)61766-8

[2] World Health Organization (2011) The Sixteenth Global Report on Tuberculosis. http://apps.who.int/iris/bitstream/10665/44728/1/9789241564380 eng.pdf

[3] World Health Organization (2015) Surveillance Report 2015. http://www.who.int/tb/publications/global report/gtbr15 main text.pdf?ua=1 
[4] European Centre for Disease Prevention and Control/WHO Regional Office for Europe. Tuberculosis Surveillance and Monitoring in Europe 2014. http://ecdc.europa.eu/en/publications/Publications/tuberculosis-surveillance-monitoring-E urope-2014.pdf

[5] Jelastopoulou, E., Alexopoulos, E.C., Venieri, D., Tsiros, G., Komninou, G., Constantinidis, T.C., et al. (2009) Substantial Underreporting of Tuberculosis in West Greece: Implications for Local and National Surveillance. Euro Surveillance, 14, pii: 19152.

[6] Lytras, T., Spala, G., Bonovas, S. and Panagiotopoulos, T. (2012) Evaluation of Tuberculosis Underreporting in Greece through Comparison with Anti-Tuberculosis Drug Consumption. PLoS One, 7, 50033. http://dx.doi.org/10.1371/journal.pone.0050033

[7] http://ecdc.europa.eu/en/ESCAIDE/programme/abstract-book/Documents/ECSAIDE-2014 -abstracts.pdf

[8] Papaventsis, D., Nikolaou, S., Karabela, S., Ioannidis, P., Konstantinidou, E., Marinou, I., et al. (2010) Tuberculosis in Greece: Bacteriologically Confirmed Cases and Anti-Tuberculosis Drug Resistance, 1995-2009. Euro Surveillance, 15, 19614.

[9] http://www.who.int/tb/challenges/mdr/en/

[10] WHO (2012) Global Tuberculosis Report 2012. WHO, Geneva. http://apps.who.int/iris/bitstream/10665/75938/1/9789241564502 eng.pdf

[11] http://www.eurosurveillance.org/ViewArticle.aspx?ArticleId=19614

[12] Wright, A., Zignol, M., Van Deun, A., Falzon, D., Gerdes, S.R., Feldman, K., et al. (2009) Epidemiology of Antituberculosis Drug Resistance 2002-07: An Updated Analysis of Global Project on Anti-Tuberculosis Drug Resistance Surveillance. The Lancet, 373, 1861-1873. http://dx.doi.org/10.1016/S0140-6736(09)60331-7

[13] Kanavaki, S., Mantadakis, E., Nikolaou, S., Papavassiliou, A., Karambela, S., Anagnostou, S., et al. (2006) Resistance of Mycobacterium tuberculosis Isolates in Different Populations in Greece during 1993-2002. The International Journal of Tuberculosis and Lung Disease, 10, 559-564.

[14] Kazdaglis, G., Gioula, G., Manika, A. and Malisiovas, N. (2012) The Epidemiology of Tuberculosis in Greece. AUMJ, 39, 19-22.

[15] http://www2.keelpno.gr/blog/?p=678

[16] http://www.eurosurveillance.org/ViewArticle.aspx?ArticleId=20430

[17] Gonzalo, X., Hutchison, D.C.S., Drobniewski, F.A., Pimkina, E. and Davidaviciene, E. (2014) Multidrug-Resistant Tuberculosis in the United Kingdom and Lithuania. The International Journal of Tuberculosis and Lung Disease, 18, 663-665.

http://dx.doi.org/10.5588/ijtld.13.0342

[18] http://www.who.int/tb/challenges/mdr/mdr tb factsheet.pdf

[19] Constantopoulos, S. (2011) Tuberculosis Control Program. HCDCP. Newsletter. Athens. http://www2.keelpno.gr/blog/?p=775\&lang=en 
Submit or recommend next manuscript to SCIRP and we will provide best service for you:

Accepting pre-submission inquiries through Email, Facebook, LinkedIn, Twitter, etc. A wide selection of journals (inclusive of 9 subjects, more than 200 journals)

Providing 24-hour high-quality service

User-friendly online submission system

Fair and swift peer-review system

Efficient typesetting and proofreading procedure

Display of the result of downloads and visits, as well as the number of cited articles

Maximum dissemination of your research work

Submit your manuscript at: http://papersubmission.scirp.org/ 